\title{
INTEGRASI PEMBERDAYAAN MAHASISWA DENGAN MASYARAKAT DESA SEPUTUK DAN DESA RIAN KABUPATEN TANA TIDUNG MELALUI OPTIMALISASI POTENSI LOKAL MELALUI REVOLUSI MENTAL MEWUJUDKAN DESA BERSIH DAN MANDIRI
}

\begin{abstract}
Student Empowerment Integration With The Community Of The Village Of Seputuk And The Village Of Tana TIidung Regency Rian Through Optimization Of Local Potential Through A Mental Revolution Embodies The Village Clean And Independent
\end{abstract}

\author{
Syahran*, Widyastuti Cahyaningrum \\ Universitas Borneo Tarakan \\ E-mail:Syahran_007@yahoo.com
}

\begin{abstract}
ABSTRAK
Permasalahan pembangunan Kabupaten Tana Tidung meliputi: permasalahan kesejahteraan masyarakat dan permasalahan pelayanan umum. Revolusi mental diharapkan dapat menjadi salah satu solusi dan ajakan mengubah cara pandang, pikiran, sikap perilaku yang berorientasi pada kemajuan dan kemodernan.PKM ini bertujuan untuk upaya rekomendasi pemerintah akan potensi yang dimiliki daerah Kalimantan Utara, sehingga dapat membantu dalam pengelolaan potensi tersebut. Metode yang digunakan adalah parsipatoris. Fokus kegiatan pengabdian pada desa Rian dan Seputuk. Berdasarkan hasil data masih banyak masyarakat dan perangkat desa yang puas dan memahami gerakan revolusi mental Indonesia bersih sebanyak 93\%. Minimnya sosialisasi gerakan revolusi mental secara massif merupakan salah satu alasan diperlukan adanya kegiatan sosialisasi gerakan revolusi mental secara massif dan berkesinambungan. Kegiatan Program Kemitraan Masyarakat berbasis Revolusi mental dengan gerakan Indonesia Bersih dan Gerakan Indonesia Mandiri di Desa Seputuk dan Desa Rian Kecamatan Muruk Rian Kabupaten Tana Tidung berjalan dengan baik.
\end{abstract}

Kata Kunci : potensi lokal, desa bersih, desa mandiri, revolusi mental

\begin{abstract}
The development problem of Tana Tidung Regency were included: the problems of community welfare and the problems of public services. The mental revolution is expected to be one of the solutions and the invitation to change the perspective, mind, behavioral attitude that is oriented to progress and modernity. The PKM was aimed recommend government efforts on the potential of North Kalimantan, so it can assist in managing that potential. The method used is parsipatoris. The focus of devotion activities in Rian and Seputuk villages. Based on the results of data, there are still many people and village apparatus that are satisfied and understand the movement of clean mental revolution of Indonesia as much as 93\%. The lack of socialization of the massive revolutionary movement is one of the reasons for the need for massive and sustainable socialization of massive mental revolutionary movements. Community Partnership Program Activities based on the mental revolution with the Movement of Clean Indonesia and Indonesia Independent Movement in Seputuk Village and Rian Village Muruk Rian Subdistrict Tana Tidung District runs well.
\end{abstract}

Keyword : local potential, clean village, independent village, mental revolution 


\section{(1) PENDAHULUAN}

Permasalahan pembangunan Kabupaten Tana Tidung pada dasarnya merupakan kesenjangan harapan (gap expectation) antara kinerja pembangunan yang telah dicapai saat ini dengan yang direncanakan serta antara apa yang ingin dicapai di masa datang dengan kondisi riil saat perencanaan dibuat. Secara umum, kesenjangan harapan yang menjadi permasalahan pembangunan di Kabupaten Tana Tidung disebabkan oleh beberapa hal sebagai berikut: (1) belum dapat mengoptimalkan kekuatan yang dimiliki; (2) belum mampu mengatasi kelemahan-kelemahan yang dimiliki; (3)belum maksimal dalam memanfaatkan peluang; dan (4) belum mampu mengatisipasi ancaman.

Hasil identifikasi dan analisis hubungan interaksi dan dinamika perkembangan berbagai sektor dapat dirumuskan permasalahan pembangunan Kabupaten Tana Tidung yang meliputi: permasalahan kesejahteraan masyarakat dan permasalahan pelayanan umum. Hal ini sangat tergambar di kecamatan muruk rian dengan desa yang memiliki potensi lokal daerah yang mampu diolah untuk pembangunan dan perekonomian desa tersebut. Muruk rian memiliki potensi lokal yang mumpuni terutama pada potensi lokal pemanfaatan lahan pertanian dengan hasil pertanian yang berlimpah dan potensi lokal seperti pariwisata desa wisata serta potensi alam air terjun yang belum optimal dimanfaatkan oleh penduduk bersama pemerintah Kabupaten Tana Tidung.

Kecamatan Muruk Rian memiliki 6 desa, yang diantaranya memiliki tingkat kemiskinan tertinggi berdasarkan data BPMPD Kabupaten Tana Tidung Tahun 2016 yaitu Rian dan Seputuk. Ketiga tersebut memiliki rata-rata $58 \%$ dari jumlah penduduk desa tersebut. Dengan kondisi infrastruktur dan fasilitas sarana prasarana yang masih terbatas (gambar 1 dan 2). Mata pencarian utama sebagian besar desa di Muruk Rian diantara tanaman pangan seperti padi, jagung, kedelai, kacang tanah, ubi kayu dan ubi jalar yang ditahun 2015 mengalami penurunan sebesar 15,65\%. Sedangkan tanaman holtikultura diantarana cabai dan tanaman buahbuahan juga mengalami penurunan produksi. Dengan kebun/sawah non irigasi maka sudah dapat di pastikan bahwa hanya dapat menghasilkan produksi ketika musim hujan saja, sementara ketika musim kemarau lahan yang ada di biarkan dan tidak diolah, dengan permasalahan tersebut diperlukan kemandirian pertanian yang kelola dengan baik. Dari potensi lokal desa seperti Desa Rian dan Seputuk merupakan salah satu desa budaya lokal yang masih memagang teguh dengan adat istiadat dan kearifan lokal serta sejarah yang belum tertata ketertiban dan banyak dikenal secara umum, sehingga menjadi potensi untuk dikembangkan. Selain potensi adat budaya, Desa rian juga memiliki wisata alam seperti Air terjun potensi lokal untuk menjadi ekowisata belum tertata kebersihannya dan promosi yang kedepannya dapat membangun kemandirian serta perekononian desa. Untuk mewujudkan pemecahan permasalahan tersebut diperlukan suatu penataan dengan gerakan aksi nyata Bersih, Tertib dan Mandiri berbasis Revolusi Mental.

Dimana revolusi mental diharapkan dapat menjadi salah satu 
solusi dan ajakan mengubah cara pandang, pikiran, sikap perilaku yang berorientasi pada kemajuan dan kemodernan, sehingga Kabupaten Tana Tidung dan khususnya Kecamatan Muruk Rian menjadi mampu berkompetisi menghadapi MEA. Hal ini juga sesuai misi Kabupaten Tana Tidung yaitu "1) memanfaatkan Memanfaatkan dan memberdayakan potensi sumber daya alam, tata ruang, dan pengelolaan lingkungan hidup yang bijaksana, adil, dan berkelanjutan; 2) Mengembangkan budaya dan pariwisata yang berbasis lokal; 3) Menjamin keamanan, sadar hukum, sebagai dasar tercapainya masyarakat yang adil dan sejahtera; 4) Membangun dan memberdayakan sentra agroindustri dalam arti luas, yang meliputi : pertanian tanaman pangan, hortikultura, peternakan, perkebunan, kehutanan dan perikanan. Dengan melalui keterpaduan tridarma perguruan tinggi melalui pemberdayaan Kermitraan masyarakat berbasis revolusi mental yang memiliki nilai integritas, etos kerja dan gotong royong menjadi alasan kami untuk mengembalikan semangat pembangunan kabupaten Tana Tidung dengan menjadi Desa Bersih, dan Mandiri.

\section{Dalam}

proses

mempraktekkkan ilmu dan menerapkan hasil penelitian yang dilaksanakan oleh civitas akedemika, maka perlu suatu media yang mendukung, kuliah kerja nyata (KKN) Revolusi mental merupakan sebuah media yang efektif dan edukatif, yaitu dengan menerjunkan mahasiswa ke tengah-tengah masyarakat, meraka akan dapat menangkap dan menghayati denyut nadi kehidupan masyarakat.
Persoalan-persoalan yang dihadapi, sumber-sumber daya yang telah dan belum dimiliki, dan solusi-solusi yang diperlukan sesuai dengan aspirasi dan harapan yang diimpikan masyarakat.

\section{(2) METODE PENELITIAN}

Metode Pelaksanaan kegiatan Program kemintraan masyarakat (PKM) terbagi dalam beberapa tahap sebagai berikut :

\section{a. Persiapan}

1. PKM ini melibatkan mahasiswa sehingga melakukan wawancara untuk menjaring mahasiswa yang benar-benar komitmen terhadap program PKM yang ditawarkan, karena perlu keseriusan terlebih bhakti mahasiswa kepada masyarakat.

2. Adapun materi yang diberikan dalam sosialisasi PKM adalah tentang sosial budaya, pemberdayaan Pendidikan, Pemberdayaan Kesehatan Masyarakat, wawasan revolusi mental, bidang administrasi baik administrasi negara maupun hukum administrasi dan teknik.

3. Survei/Observasi ke lokasi, mitra dan kelompok masyarakat yang dijadikan sasaran PKM.yaitu di Kecamatan Muruk Rian dengan fokus , Desa Rian dan Desa Seputuk. 4. Mengkomunikasikan program PKM dengan pemerintah daerah setempat, serta mitra lainnya dengan cara sosialisasi dan pendampingan kepada masyarakat.

5. Membuat persetujuan dari kesepakatan kerjasama dengan Badan Pemberdayaan Masyarakat Desa (BPMD) Kabupaten Tana Tidung. 


\section{b. Pelaksanaan Pengabdian Kepada Masyarakat (PKM)}

Kegiatan akan dilaksanakan menggunakan metode partisipatoris. Jadi, pelaksanaan program dilakukan dengan melibatkan masyarakat setempat dan mahasiswa Kuliah Kerja Nyata sebagai fasilitator. Untuk itu, diperlukan pendampingan dalam setiap kegiatan agar dapat diketahui dinamika dari kegiata tersebut sehingga dapat mewujudkan tujuan pemberdayaan. Adapun kegiatan yang di rancang adalah:

1. Bimbingan teknis/Pendampingan/Penyuluh an berupa aktivitas kegiatan Pertanian mahasiswa bersama masyarakat;

2. Aktivitas pendukung lainnya dalam rangka mengembangkan Kesadaran kebersihan, kesehatan dan lingkunga serta nasionalisme dengan program Gerakan Indonesia melayani dan Gerakan Indonesia Mandiri.

Kegiatan Peningakatan kapasitas masyarakat di Desa Rian dan Desa Seputuk di Kabupaten Tana Tidung Provinsi Kalimantan Utara ini dapat terus menerus dengan memasukannya kegiatan pengabdian pada masyarakat yang dilakukan melalui kegiatan Program kemintraan masyarakat (PKM), sehingga dapat mengoptimalkan potensi mahasiswa setiap tahunnya. Melalui program pertanian, setelah implementasi program PKM terlaksana, diharapkan masyarakat wilayah Kabupaten Tana Tidung lebih mandiri dalam mengolah potensi lokal yang ada, sehingga hasilnya lebih optimal. Selain itu, program ini juga diharapkan dapat membuat masyarakat menjadi lebih cerdas dan kaya akan ilmu yang menunjang pengolah potensi tersebut dan dapat mewujudkan kesejahteraan. Program kedua, peningkatan sumber daya manusia dalam bidang pendidikan dan kesehatan. Program di bidang pendidikan ini diharapkan dapat meningkatan kesadaran akan pendidikan dan minat membaca pada generasi penerus sehingga dapat membuka wawasan dan ilmu pengetahuan. Sementara dalam bidang kesehatan, masyarakat diharapkan dapat meningkatan kesadaran akan pentingnya kesehatan. Dengan program peningkatan kualitas lingkungan, masyarakat diharapkan dapat lebih bertanggung jawab dalam pemeliharan lingkungan. Program terakhir yaitu pemetaan potensi lokal yang ada agar dapat menjadi refrensi dalam pembangunan desa.

Program ini diharapkan dapat dijadikan rekomendasi untuk pemerintah akan potensi yang dimiliki daerah Kalimantan Utara, sehingga dapat membantu dalam pengelolaan potensi tersebut. Keberlanjutan program perlu di komunikasikan dengan pihak BPMD Se Kalimantan Utara, sehingga dapat dilakukan secara luas dengan melibatkan Tim LPPM-selaku penyelenggara PKM Universitas Borneo Tarakan dalam setiap kegiatan pelatihan dan pendampingan. Selain itu, tindak lanjut program yang berhubungan dengan pengelolaan program dilakukan dengan mengoptimalkan peran BPMD KTT untuk mendukung keberlanjutan usaha yang dikembangkan, serta lokasi akan diusulkan sebagai Desa Binaan Universitas Borneo Tarakan. 


\section{(3) HASIL PENELITIAN}

A. Aksi Revolusi Mental Gerakan Indonesia Bersih

Gerakan Indonesia Bersih

(GIB) Program ini fokus pada peningkatan perilaku hidup bersih dan sehat lingkungan keluarga, satuan pendidikan, satuan kerja, dan komunitas, peningkatan sinergi penyediaan sarana dan prasarana yang menunjang perilaku hidup bersih dan sehat. Kebersihan lingkungan dapat berawal dari siapapun termasuk dari lingkungan rumah sendiri. Lingkungan akan lebih baik jika semua orang sadar dan bertanggungjawab akan kebersihan lingkungan, karena hal itu harus ditanamkan sejak dini, di sekolah pun kita diajarkan untuk selalu hidup bersih.

Seperti halnya kegiatan pengabdian masyarakat yang dilakukan di Desa Seputuk dan Desa Rian Kecamatan Muruk Rian Kabupaten Tana Tidung, dimana kegiatan meliputi pengadaan tempat sampah di sekitar lingkungan desa, Pembuatan dan sosialisasi tanaman Toga, Pengecatan Fasilitas umum yang terlihat kumuh, Pembuatan MOL, Pemberian alat kebersihan dan tong sampah Sosialisasi bahaya narkoba dan program kerja bakti. Berikut ini kegiatan dokumentasi gerakan Indonesia bersih Desa Seputuk dan Desa Rian Kecamatan Muruk Rian Kabupaten Tana Tidung.

Berdasarkan data kepuasan dan pemahaman gerakan revolusi mental Indonesia bersih maka kemudian dilakukan wawancara kepada masyarakat dan perangkat desa yang puas dan belum memahami gerakan revolusi mental Indonesia bersih, namun pernah menerapkan. Berdasarkan hasil data masih banyak masyarakat dan perangkat desa yang puas dan memahami gerakan revolusi mental Indonesia bersih sebanyak 93\%. Minimnya sosialisasi gerakan revolusi mental secara massif merupakan salah satu alasan diperlukan adanya kegiatan sosialisasi gerakan revolusi mental secara massif dan berkesinambungan agar masyarakat memahami dan berdampak akan perubahan tingkah laku di masyarakat kecamatan Muruk Rian.

Kegiatan Pengabdian berbasis revolusi Mental merupakan integrasi mahasiswa dengan dosen memfokus spesifik berbasis pada nilai-nilai strategi Revolusi Mental, yaitu integritas, etos kerja, dan gotong royong, dengan implementasi melalui sikap/ perilaku hidup bersih. Dalam proses mempraktekkkan ilmu dan menerapkan hasil penelitian yang dilaksanakan oleh civitas akedemika, maka perlu suatu media yang mendukung, pengabdian berbasis Revolusi mental merupakan sebuah media yang efektif dan edukatif, meraka akan dapat menangkap dan menghayati denyut nadi kehudupan masyarakat. Melalui gerakan Indonesia Bersih KKNRevolusi Mental Universitas Borneo Tarakan Menuju kesadaran dan kepedulian baik masyarakat maupun pemerintahan desa terhadap kebersihan lingkungan.

\section{B. Aksi Revolusi Mental Gerakan Indonesia Mandiri Gerakan Indonesia Mandiri} (GIMa) adalah gerakan para Penyelenggara Negara dan masyarakat untuk mendorong budaya kreatif, inovatif, dan beretos kerja tinggi untuk meningkatkan produktivitas dan daya saing bangsa. 
Gerakan ini akan mendorong terwujudnya kemandirian dalam berbagai sektor kehidupan, seperti pertumbuhan kewirausahaan dan ekonomi kreatif, peningkatan UMKM dan koperasi, peningkatan apresiasi seni, kreativitas karya budaya dan warisan budaya. Peningkatan kemandirian terutama nilai etos kerja merupakan faktor strategis dalam menghadapi persaingan regional dan global. Gerakan ini dilakukan oleh para penyelenggara negara dan masyarakat yang saling bersinergi untuk mewujudkan kemandirian bangsa di berbagai sektor kehidupan.

Seperti halnya kegiatan pengabdian masyarakat yang dilakukan di Desa Seputuk dan Desa Rian Kecamatan Muruk Rian Kabupaten Tana Tidung, dimana kegiatan Gerakan Indonesia Mandiri meliputi Pemberdayaan potensi lokal dengan membuat usaha kolam terpal, Sosialisasi dan Bimbingan teknis terkait ilmu pengetahuan dan teknologi dalam meningkatkan promosi usaha yang telah di tekuni, dan melakukan sosialisasi UMKM untuk mendorong terbentuknya BUMDES di desa. Harapan dengan adanya kegiatan Gerakan Indonesia Mandiri di desa Desa Seputuk dan Desa Rian Mewujudkan desa yang berdaulat dan mandiri secara ekonomi, dan berkepribadian yang kuat melalui pembentukan manusia Indonesia baru yang unggul menerapkan nilai-nilai integritas, kerja keras, dan semangat gotong royong. Berikut ini kegiatan gerakan Indonesia Mandiri di Desa Seputuk dan Desa Rian Kecamatan Muruk Rian Kabupaten Tana Tidung.

Gerakan Indonesia Mandiri, adalah gerakan untuk mewujudkan perilaku kreatif, inovatif, dan beretos kerja tinggi agar mewujudkan kemandirian dibidang pangan, energi, dan teknologi dalam menghadapi persaingan regional dan global. Gerakan Indonesia Mandiri di Desa Seputuk dan Desa Rian Kecamatan Muruk Rian Kabupaten Tana Tidung terfokus pada Mendukung dan mendorong kewirausahaan serta ekonomi kreatif memberdasarkan potensi lokal, Melakukan pengembangan teknologi tepat guna untuk mendorong ekonomi kreatif, Melakukan identifikasi dan pemanfaatan potensi sumber daya alam daerah tertinggal.. Dalam Pelaksanaan Gerakan Indonesia Mandiri mengandung nilai instrumental revolusi mental yaitu nilai Etos kerja dan Gotong Royong. Dimana nilai etos kerja merupakan semangat kerja yang menjadi ciri khas dan keyakinan seseorang atau masyarakat di Desa Seputuk dan Desa Rian dengan memberdayakan potensi lokal masyarakat meningkatkan nilai daya saing, kreatif, mandiri, inovatif dan produktif sehingga mewujudkan, mendorong, mendukung, dan meningkatkan kewirausahaan, serta ekonomi kreatif masyarakat desa.

Pelaksanaan kegiatan

Program Kemitraan Masyarakat berbasis Revolusi mental dengan gerakan Indonesia Bersih dan Gerakan Indonesia Mandiri di Desa Seputuk dan Desa Rian Kecamatan Muruk Rian Kabupaten Tana Tidung, Hendaknya lebih berkoordinasi dan memperlancar komunikasi dengan Pemerintah Daerah setempat terkait dengan pelaksanaan Program revolusi mental agar lebih optimal dan diikuti oleh seluruh warga masyarakat. 


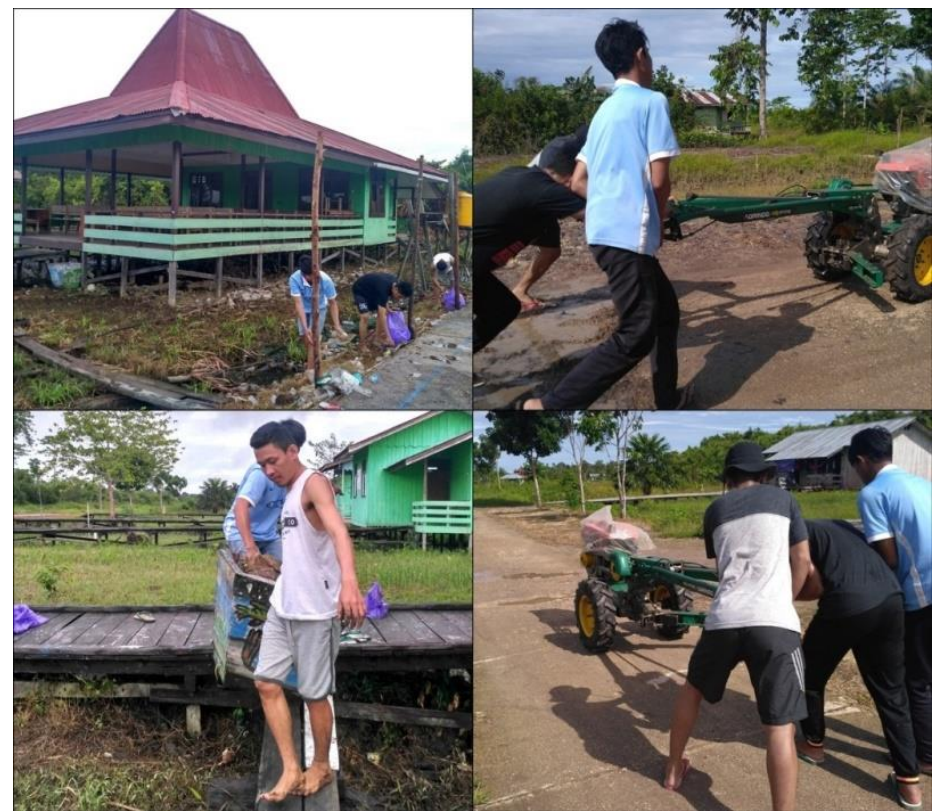

Gambar 1 Kegiatan Kerja bakti di Desa Seputuk dan Desa Rian yang diikuti oleh warga Desa

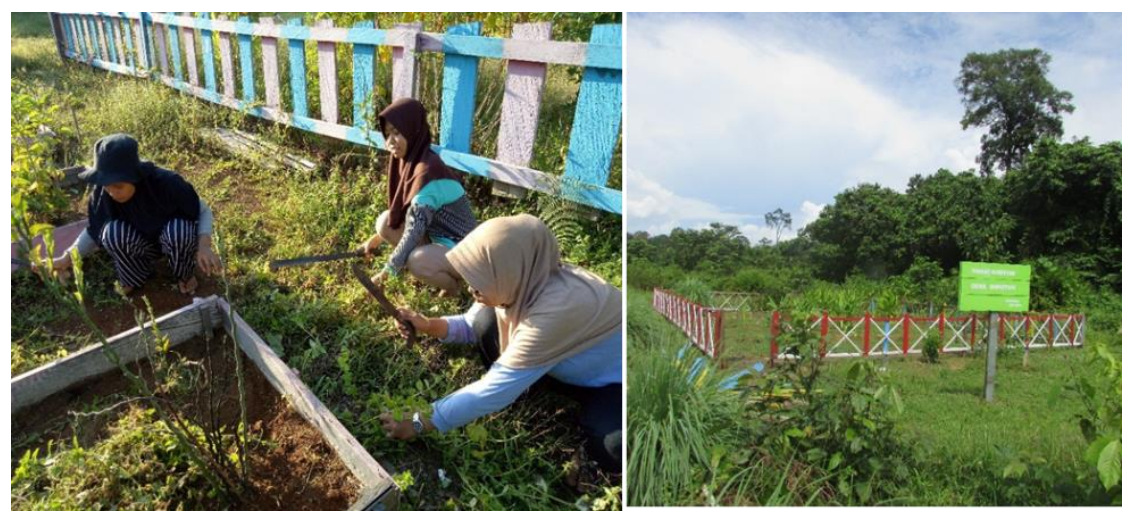

Gambar 2. Pembuatan Toga di Desa Seputuk dan Desa Rian yang diikuti oleh warga Desa
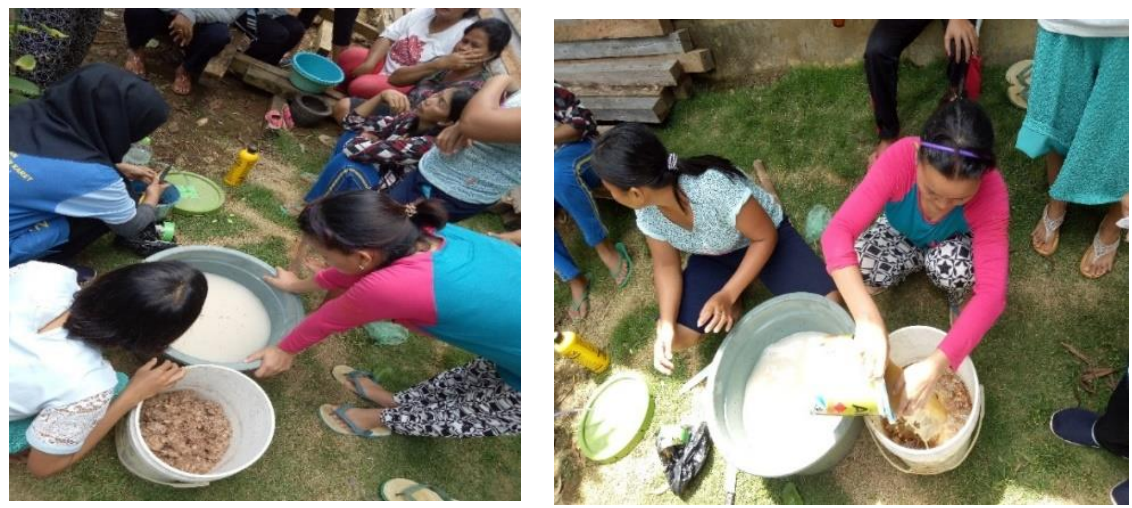

Gambar 3. Sosialisasi Pembuatan MOL dari Bahan Limbah Organik 

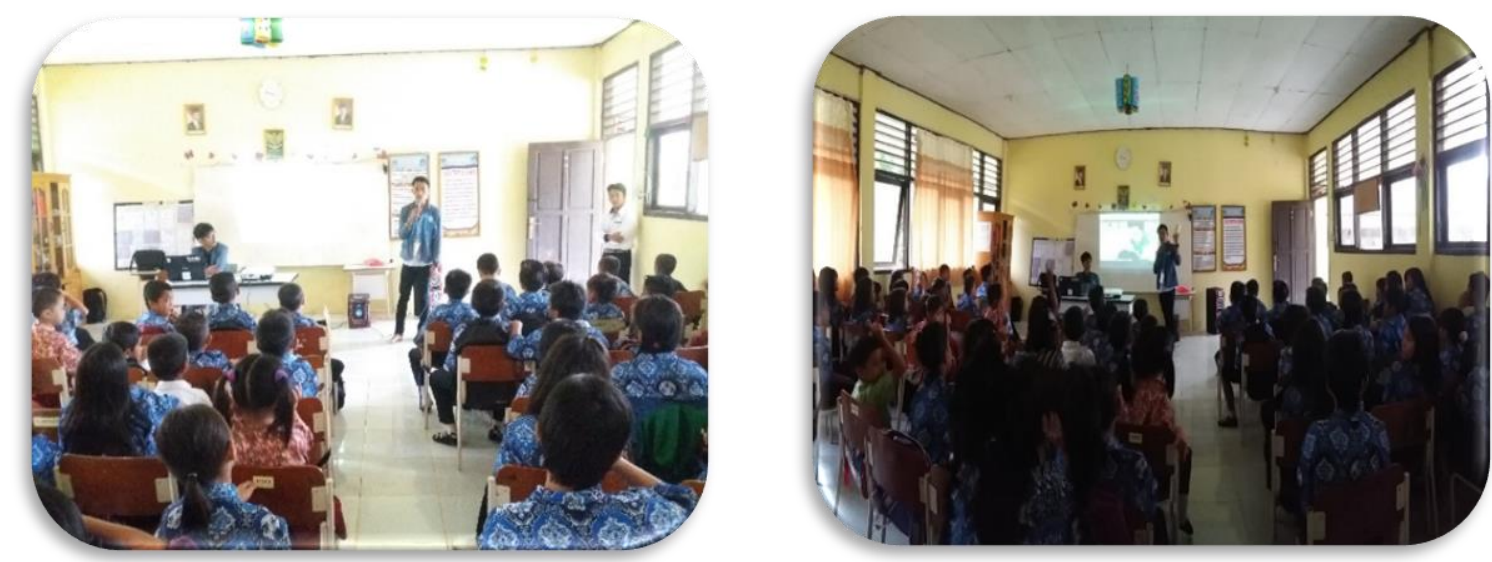

Gambar 4. Sosialisasi bahaya narkoba
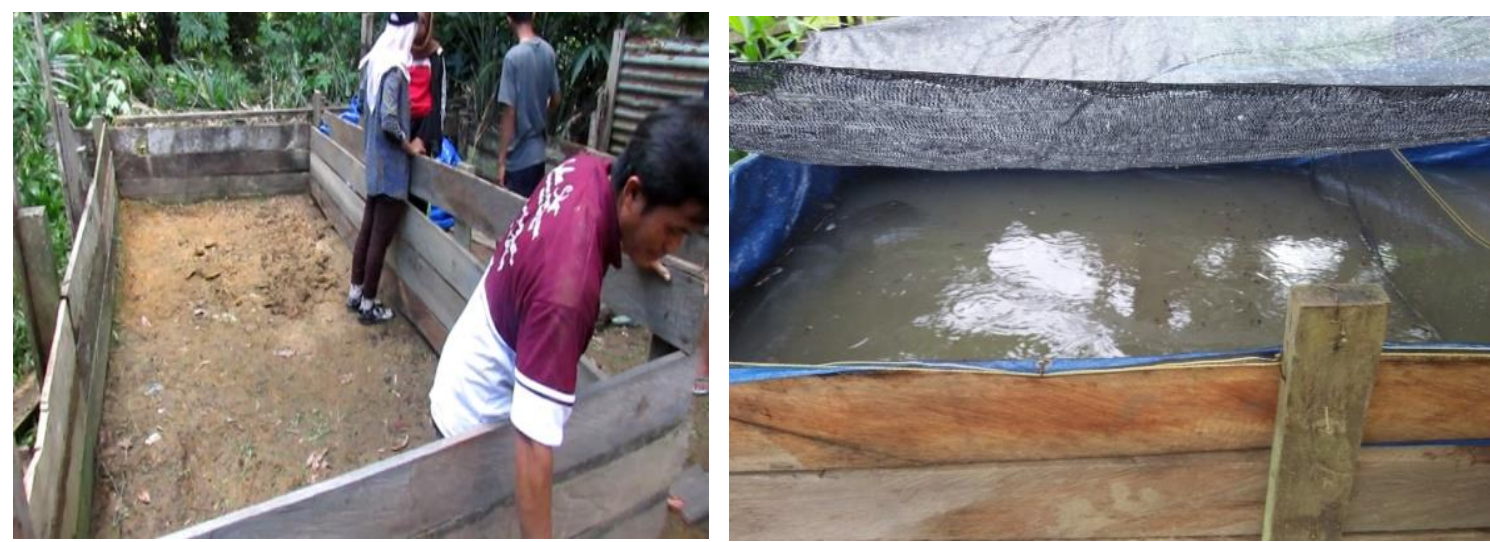

Gambar 5. Sosialisasi dan Membuat Kolam Terpal Budidaya Ikan Air tawar
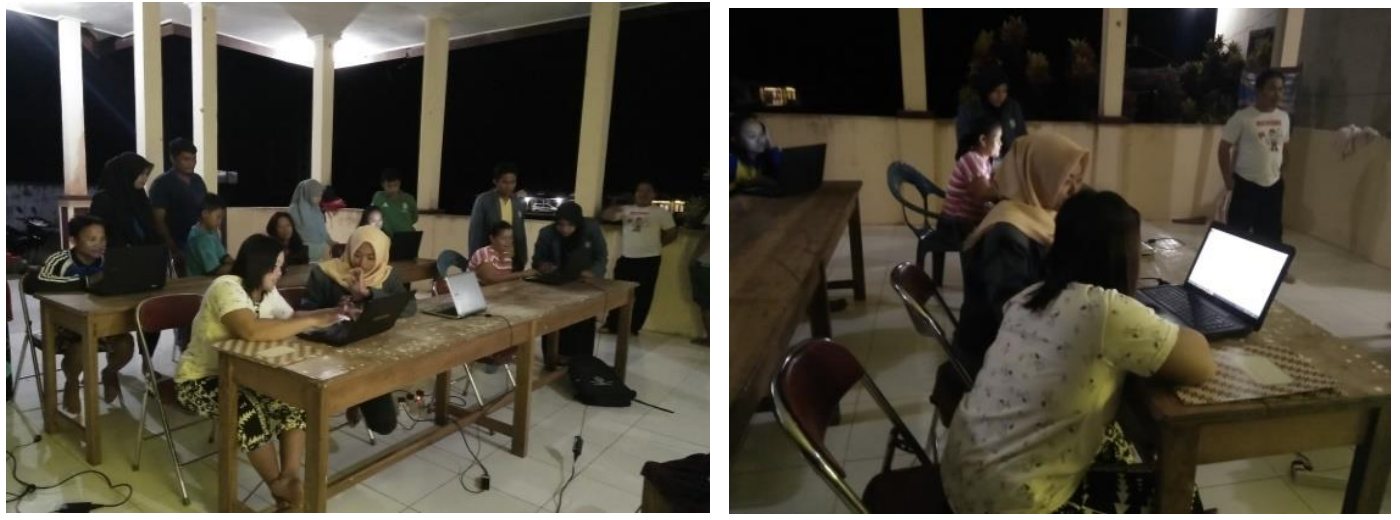

Gambar 6. Sosialisasi dan Workshop Pemanfaatan Teknologi Untuk Usaha 

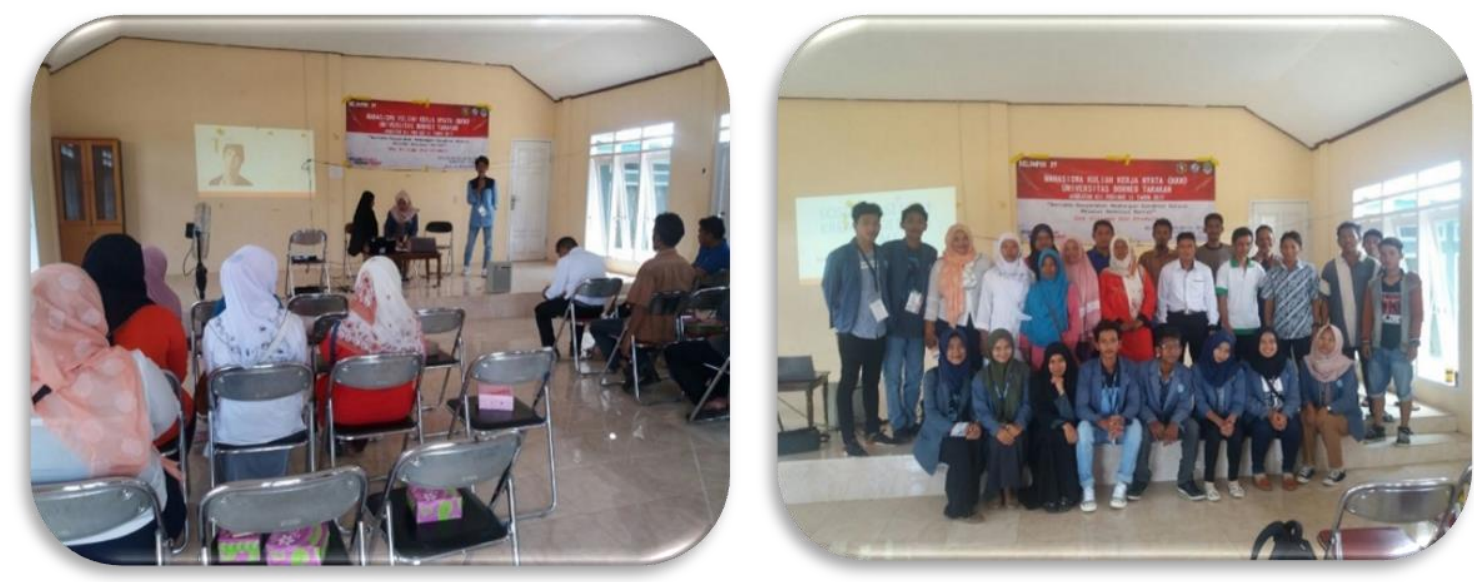

Gambar 7. Sosialisasi UMKM Kreatif Mandiri

\section{(4) KESIMPULAN}

Kegiatan Program Kemitraan Masyarakat berbasis Revolusi mental dengan gerakan Indonesia Bersih dan Gerakan Indonesia Mandiri di Desa Seputuk dan Desa Rian Kecamatan Muruk Rian Kabupaten Tana Tidung berjalan dengan baik. Kegiatan tersebut melibatkan mahasiswa dan masyarakat di desa tersebut. Program Kemitraan Masyarakat berbasis Revolusi mental Melatih masyarakat dan memberikan pembekalan ilmu pengetahuan untuk mengembangkan potensi yang dimiliki, baik potensi alam maupun potensi yang ada di dalam diri masyarakat.

Melalui gerakan Indonesia Bersih Program Kemitraan Masyarakat Revolusi Mental Universitas Borneo Tarakan Menuju kesadaran dan kepedulian baik masyarakat maupun pemerintahan desa terhadap kebersihan lingkungan. Sedangkan gerakan Indonesia mandiri terfokus pada pada pemanfaatan potensi sumber daya alam daerah tertinggal, Mendukung dan mendorong kewirausahaan serta ekonomi kreatif memberdaakan potensi lokal, dan Melakukan pengembangan teknologi tepat guna untuk mendorong Usaha ekonomi kreatif.

\section{(5) REFERENSI}

Katalog Badan Pusat Statistik. 2016. Kabupaten Tana Tidung Dalam Angka 2016. BPS. Kabupaten Tana Tidung

Tim Penyusun RPJMD.2016. Rencana Pembangunan Jangka Menengah Daerah (RJMD). Bappeda. Kabupaten Tana Tidung

Undunsyah.2016. Materi Pembekalan KKN; aasan Kabupaten Tana Tidung. Bappeda. Kabupaten Tana Tidung 